\title{
Tracing mantle heterogeneity by potassium isotope geochemistry
}

\author{
FANG-ZHEN TENG ${ }^{1 *}$, YAN HU ${ }^{1}$, ZE-ZHOU WANG ${ }^{1,2}$, \\ HENG-CI TIAN ${ }^{1,3,4}$
}

${ }^{1}$ Isotope Laboratory, Dept. of Earth and Space Sciences, University of Washington, Seattle, WA 98195, USA email: fteng@u.washington.edu

${ }^{2}$ State Key Laboratory of Geological Processes and Mineral Resources, China University of Geosciences, Beijing 100083, China

${ }^{3}$ Key Laboratory of Earth and Planetary Physics, Institute of Geology and Geophysics, CAS, Beijing 100029, China

${ }^{4}$ Innovation Academy for Earth Science, CAS, Beijing 100029, China

Subduction recycles marine sediments and oceanic crust into the mantle. However, tracing their fates in the mantle is not always straightforward as geochemical signatures of subducted sediments often dominate those of mantle-derived samples. Here we present the first systematic investigation on compositions and controls of $\mathrm{K}$ isotopic variations in subducting oceanic slabs as well as well-characterized basaltic lavas from different tectonic settings. Our results reveal large $\mathrm{K}$ isotopic variation in the subducting slabs and $\mathrm{K}$ isotope geochemistry can be used to differentiate subducted sediments from altered oceanic crust in mantle-derived lavas.

Our globally-sampled subducting sediments around major trench systems display over $2 \% \mathrm{~K}$ isotopic heterogeneity in the subducting slab, with altered basalts enriched in heavy $\mathrm{K}$ isotopes and marine sediments in light isotopes. The large isotopic variation reflects the diversity of fractionation mechanisms operating in marine environments. Once subducted, these highly K-enriched crustal lithologies are able to imprint their distinctive $\mathrm{K}$ isotopic signatures to mantle-derived magmas as illustrated by studies of continental basaltic lavas from the Northeast China, oceanic island basalts from Hawaii, island arc lavas from Lesser Antilles and continental arc lavas from Cascades. The over $1 \% \mathrm{~K}$ isotopic variation in mantle-derived lavas, together with geochemical data obtained in earlier studies, cannot be ascribed to chemical weathering, crystal fractionation, crustal contamination, or partial melting, but are consistent with the presence of diverse crustal materials in magma sources. Recycled oceanic crust and sediments both have contributed to the contrasting $\mathrm{K}$ isotopic signature observed in these lavas. Our studies highlight the potential of using $\mathrm{K}$ isotopes to trace different types of recycled crustal materials in the mantle and place new constraints on the generation of enriched mantle reservoirs. 